\title{
OPTIMALISASI SUMBER DAYA KOMPUTER DENGAN VIRTUALISASI SERVER MENGGUNAKAN PROXMOX VE
}

\author{
Abdurrahman ${ }^{1}$, Soni ${ }^{2}$, Afdhil Hafid ${ }^{3}$ \\ ${ }^{1,2,3}$ Program Studi Teknik Informatika, Fakultas Ilmu Komputer, Universitas Muhammadiyah Riau \\ Jl. KH. Ahmad Dahlan No. 88, Sukajadi, Pekanbaru \\ Telp (0761) 35008 \\ Email : Abdurrahman@student.umri.ac.id ${ }^{1}$, soni@umri.ac.id² afdhilhafid@umri.ac.id $^{3}$
}

\begin{abstract}
Virtualization technology is a topic that began to be scrutinized by researchers. This is inseparable from the technology's ability to reduce the cost of providing infrastructure and operations independently for each service to be served. With server virtualization, we can make several computers into one, which used to be possible for server computers to have three physical computers that can be used as one for the three server computers which in fact the resources on a single physical server computer will not use all the resources in one single physical computer. The existence of proxmox, then all servers can be connected in a network together so that they are able to streamline time. In addition, Proxmox has a web console that can be used for various purposes in server virtualization and maintenance. In this study, the performance of server virtualization using ProxmoxVE will be examined. This study is intended to determine the load of memory usage, load the CPU when running all the servers in Proxmox, and examine the Throughput, PacketLoss, Delay and Jitter on the server.
\end{abstract}

\section{Keyword: Proxmox, Virtualization, Resources, Server, Operating System}

Abstrak: Teknologi virtualisasi merupakan topik yang mulai ramai diteliti oleh para peneliti. Hal tersebut tidak terlepas dari kemampuan teknologi tersebut dalam memangkas biaya penyediaan infrastruktur dan operasional secara mandiri bagi setiap servis yang akan dilayani. Dengan adanya virtualisasi server maka kita bisa menjadikan beberapa komputer menjadi satu, yang tadinya mungkin komputer server ada tiga unit komputer fisik bisa dijadikan menjadi satu untuk ketiga komputer server tersebut yang pada kenyataannya resource pada komputer server fisik tunggal juga tidak akan memakai semua resource yang ada di satu komputer fisik tunggal tersebut. Adanya proxmox, maka semua server dapat terhubung dalam suatu jaringan menjadi satu secara konstan sehingga mampu mengefesien waktu. Selain itu proxmox memiliki web console yang bisa digunakan umtuk berbagai keperluan dalam virtualisasi dan maintenance server. Dalam penelitian ini, akan diteliti performa dari virtualisasi server menggunakan ProxmoxVE. Penelitian ini dimaksudkan untuk mengetahui beban penggunaan memory, Load CPU pada saat dijalankan semua server yang ada di dalam proxmox tesebut dan meneliti Throughput, PacketLoss, Delay dan Jitter yang ada pada server.

Kata Kunci: Proxmox, Virtualisasi, Sumber Daya, Server, Sistem Operasi

\section{PENDAHULUAN}

Pada masa sekarang ini, teknologi virtualisasi merupakan topik yang mulai ramai diteliti oleh para peneliti. Hal tersebut tidak terlepas dari kemampuan teknologi tersebut dalam memangkas biaya penyediaan infrastruktur dan operasional secara mandiri bagi setiap servis yang akan dilayani. Melalui teknologi ini, sebuah layanan dapat dikonfigurasikan tanpa mempengaruhi konfigurasi dari layanan lainnya meskipun dalam satu mesin fisik yang sama. Dengan teknologi ini satu mesin fisik dijadikan sebuah sumber daya bersama yang dapat dibagi dan dipakai oleh beberapa layanan sekaligus. Masing-masing layanan dapat memiliki sistem operasi sendiri-sendiri. Setiap layanan tersebut ditempatkan dalam sebuah wadah atau kontainer. Karena memiliki sistem operasi sendiri pada masing-masing layanannya, 
konfigurasi dari masing-masing layanan pun tidak saling mempengaruhi.

Aplikasi virtualisasi membantu memecahkan masalah ketidakmampuan aplikasi dalam suatu sistem operasi dan lainnya dengan menambahkan lapisan isolasi antara sistem operasi dan aplikasi. Pendekatan virtualisasi ini memberi administrator cara untuk membuat virtualisasi aplikasi yang membantu meminimalkan risiko, menghemat waktu, meningkatkan kepuasan pengguna, dan mengurangi biaya pengujian ${ }^{[1]}$.

Virtualisasi adalah suatu teknologi pada sebuah perangkat lunak yang memungkinkan satu perangkat keras untuk menjalankan beberapa sistem operasi dan servis pada saat yang sama. Layanan-layanan server dijalankan pada mesin-mesin server virtual di dalam mesin server fisik. Jumlah layanan yang banyak, data-data penting, dan tingkat ketergantungan kinerja dari perusahaan, instansi atau organisasi yang tinggi terhadap layanan server membuat server harus dapat melayani secara terus menerus ${ }^{[2]}$.

Saat ini, virtualisasi memegang peranan yang sangat penting dalam dunia teknologi informasi. Hal ini dibuktikan dengan banyaknya perusahaan yang telah menggunakan virtualisasi ${ }^{[3]}$.

Dengan adanya virtualisasi server maka kita bisa menjadikan beberapa komputer menjadi satu, yang tadinya mungkin komputer server ada tiga unit komputer fisik bisa dijadikan menjadi satu untuk ketiga komputer server tersebutyang pada kenyataannya resource pada komputer server fisik tunggal juga tidak akan memakai semua resource yang ada di satu komputer fisik tunggal tersebut.

Saat ini, ada berbagai macam server produk virtualisasi. Proxmox adalah salah satunya produk, tetapi memiliki keunggulan utama pesaing dengan memiliki lisensi gratis yang hamper fitur yang sama dengan pesaing. Ini salah satunyaalasan mengapa banyak pengguna memilih Proxmox ${ }^{[4]}$.

\section{LANDASAN TEORI}

1. Proxmox Virtual Environment

Proxmox Virtual Environment

(ProxmoxVE) merupakan sistem operasi mesin virtual yang mulai banyak dipakai oleh para pengguna teknologi virtualisasi. Hal ini dikarenakan sistem operasi tersebut bersifat Open source sehingga lebih mudah untuk dimodifikasi dan dikembangkan. ProxmoxVE merupakan sistem operasi turunan Linux Debian dengan kernel RHEL yang telah dimodifikasi agar dapat membuat, menjalankan, dan mengatur mesin virtual. ProxmoxVE mendukung dua tipe virtualisasi yaitu virtualisasi yang berbasis kontainer OpenVZ dan virtualisasi penuh dengan $K V M$. ProxmoxVE dilengkapi dengan antarmuka pengaturan berbasis web, sehingga memudahkan untuk mengontrol kapan saja dan dari platform apapun. ProxmoxVE juga dilengkapi dengan alat bantu command line dan REST API untuk alat bantu pihak ketiga. Fitur-fitur yang ditawarkan oleh ProxmoxVE antara lain High Availability Cluster, Live Migration, bridged networking, flexible storage, OS template building, scheduled backup, dan command line tools ${ }^{[5]}$.

\section{Sistem Operasi}

Sistem operasi adalah program yang bertindak sebagai perantara antara user dengan perangkat keras komputer. Sistem operasi digunakan untuk mengeksekusi program user dan memudahkan menyelesaikan permasalahan user. Selain itu dengan adanya sistem operasi membuat sistem komputer nyaman digunakanAdapun pengembangan markerless yang telah di kembangkan oleh pengembang terbesar di dunia seperti ${ }^{[6]}$.

Sistem Operasi adalah seperangkat program yang mengelola sumber daya perangkat keras dan menyediakan layanan umum untuk aplikasi perangkat lunak. Tanpa Sistem Operasi, pengguna tidak dapat menjalankan program aplikasi pada komputer mereka, kecuali program aplikasi booting. Sistem Operasi adalah perangkat lunak sistem yang bertugas untuk melakukan control dan manajemen perangkat keras serta operasioperasi dasar sistem, termasuk menjalankan perangkat lunak aplikasi seperti programprogram pengolah kata. Secara umum, Sistem Operasi adalah perangkat lunak pada lapisan pertama yang ditempatkan pada memori komputer pada saat komputer dinyalakan. Sedangkan perangkat lunak lainnya dijalankan setelah Sistem Operasi berjalan, dan Sistem Operasi akan melakukan layanan inti untuk perangkat lunak tersebut. Layanan inti tersebut seperti akses ke disk, manajemen memori, penjadwalan tugas (schedule task), dan antarmuka user GUI/CLI. Sehingga masing-masing 
perangkat lunak tidak perlu lagi melakukan tugas-tugas inti umum tersebut, karena dapat dilayani dan dilakukan oleh Sistem Operasi. Bagian kode yang melakukan tugas-tugas inti dan umum tersebut dinamakan dengan "kernel" suatu Sistem Operasi ${ }^{[7]}$.

Sistem Operasi secara umum terdiri dari beberapa bagian:

1. Mekanisme Boot, yaitu meletakkan kernel ke dalam memory.

2. Kernel, yaitu inti dari sebuah Sistem Operasi.

3. Command Interpreter atau shell, yang bertugas membaca input dari pengguna

4. Pustaka-pustaka, yaitu yang menyediakan kumpulan fungsi dasar dan standar yang dapat dipanggil oleh aplikasi lain.

5. Driver untuk berinteraksi dengan hardware eksternal, sekaligus untuk mengontrolnya.

\section{Teknologi Virtualisasi}

Virtualisasi adalah sebuah teknik atau cara untuk membuat sesuatu dalam bentuk abstrak/virtual. Pengelola virtualisasi biasa disebut sebagai hypervisor, merupakan jenis perangkat lunak yang menciptakan "mesin virtual" yang beroperasi secara terpisah dari satu sama lain pada komputer umum. OpenVZ adalah solusi virtualisasi yang dikembangkan oleh SWsoft. OpenVZ membuat beberapa Virtual Private Server (VPS) yang terosilasi pada satu server fisik untuk berbagi hardware dan manajemen dengan efisiensi maksimum. Setiap VPS melakukan dan mengeksekusi persis seperti server yang berdiri sendiri untuk penggunanya dan aplikasinya bisa di-restart secara independent dan memiliki akses root sendiri, pengguna, alamat $I P$, memori, proses, file, aplikasi, system libraries, dan konfigurasi file-file $^{[6]}$.

Virtualisasi merupakan fundamental dari teknologi cloud, dengan adanya virtualisasi dalam satu fisik data center bisa diciptakan, digunakan, dan dihapus ribuan virtual server. Secara umum virtualisasi adalah proses konversi sumber daya Teknologi Informasi secara fisik menjadi sumber daya virtual, beberapa sumber daya yang divirtualisasi antara lain: server, storage, network, dan power. Virtual server biasa disebut juga dengan Virtual Machine ${ }^{[2]}$.

\section{Server}

Server adalah sebuah sistem komputer yang menyediakan jenis layanan tertentu dalam sebuah jaringan komputer. Terkadang istilah server disebut sebagai web server. Namun umumnya orang lebih suka menyebutnya sebagai 'server' saja. Sebuah server didukung dengan prosesor yang bersifat scalable dan $R A M$ yang besar, juga dilengkapi dengan sistem operasi khusus. Sistem operasi ini berbeda dengan sistem operasi yang biasanya. Jika kita biasa menggunakan system operasi windows, MacOS dll, maka sistem operasi dari server ini mungkin berbeda ${ }^{[8]}$.

Server adalah sebuah sistem komputer yang menyediakan jenis layanan tertentu dalam sebuah jaringan komputer. Server didukung dengan prosesor yang bersifat scalable dan $R A M$ yang besar, juga dilengkapi dengan sistem operasi khusus, yang disebut sebagai sistem operasi jaringan atau network operating sistem. Server juga menjalankan perangkat lunak administratif yang mengontrol akses terhadap jaringan dan sumber daya yang terdapat di dalamnya, seperti halnya berkas atau alat pencetak (printer), dan memberikan akses kepada workstation anggota jaringan ${ }^{[9]}$.

\section{METODELOGI PENELITIAN}

\section{Metode Penelitian}

Dalam perancangan virtualisasi server peneliti menggunakan beberapa metode. Beberapa metode tersebut adalah sebagai berikut :

\section{Metode Literatur}

Metode literatur merupakan, penelusuran literatur yang bersumber dari buku, media, pakar ataupun dari hasil penelitian orang lain yang bertujuan untuk menyusun dasar teori yang digunakan dalam melakukan penelitian.

2. Eksperimen

Pada metode ini peneliti melakukan beberapa tahap yaitu observasi, desain dan perancangan sistem, pengujian sistem yang telah dibuat. 


\section{Kerangka Konsep Penelitian}

Kerangka konseptual merupakan suatu bentuk kerangka berpikir yang dapat digunakan sebagai pendekatan dalam memecahkan masalah. Biasanya kerangka penelitian ini menggunakan pendekatan ilmiah dan memperlihatkan hubungan antar variabel dalam proses analisisnya. Adapun gambar kerangka berpikir dalam penelitian ini seperti pada Gambar 3.1

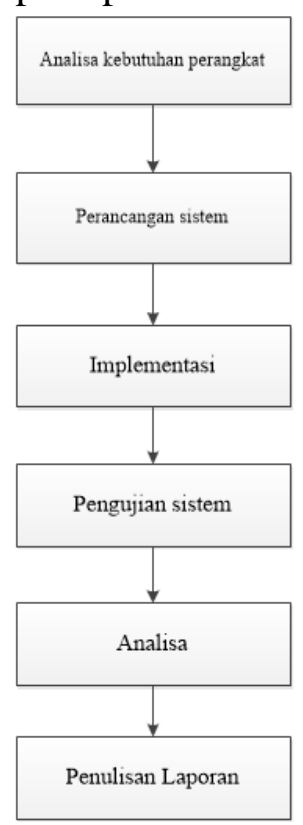

Gambar 1 : Kerangka konsep penelitian

\section{Metode Pengumpulan Data}

Pengumpulan data merupakan langkah awal dalam melakukan suatu penelitian. Pengumpulan data yang digunakan pada penelitian ini menggunakan metode observasi dan studi literatur.

a. Observasi, merupakan metode pengumpulan data dengan melakukan pengamatan secara langsung terhadap objek yang berkaitan dengan penelitian. Pada penelitian ini penulis melakukan pengamatan di situs-situs bersejarah yang ada di kota Pekanbaru

b. Studi Literatur, Pada tahap ini pengambilan referensi - referensi dari berbagai sumber yaitu jurnal penelitian terdahulu dan media internet yang membahas tentang aplikasi augmented reality berbasis android yang dapat menjadi acuan dan penunjang dalam penelitian.

\section{HASIL DAN PEMBAHASAN}

\section{Implementasi Sistem}

Distro special yang digunakan untuk virtualisasi kali ini adalah Proxmox VE (Virtual Environment), berjalan dalam modus teks dan merupakan distro debian. Meskipun berbasis teks proses manajemen pada Proxmox VE bisa juga dilakukan melalui akses web termasuk dalam melakukan instalasi sistem menggunakan teknologi VNC. Pada penelitian ini peneliti menggunakan Proxmox VE 5.3

Beberapa hal yang perlu diperhatikan terkait Proxmox sebagai berikut :

1. Proxmox disediakan hanya untuk mesin x86_64 sehingga tidak bisa digunakan pada mesin 32 bit.

2. Pada saat instalasi, Proxmox diinstalasi langsung dari CD dan akan menghapus semua isi harddisk sehingga jika ingin sekedar mencoba Proxmox sebaiknya gunakan harddisk kosong atau jalankan pada mesin Virtual.

3. Jika ingin menggunakan KVM, Proxmox membutuhkan motherboard/CPU yang mendukung teknologi virtualisasi yaitu Intel VT/AMD-V.

\section{Design Perancangan}

Berikut ini merupakan gambaran perancangan fisik laboratorium yang menghubungkan antar client atau user ke server utama.

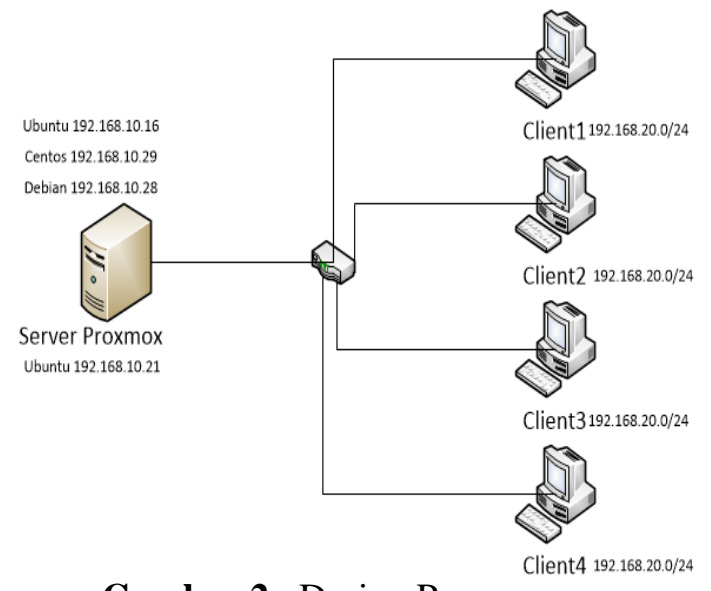

Gambar 2 : Design Perancangan 


\section{Perancanaan Skenario Pengujian}

Dalam tahap ini, cloud computing dengan virtualisasi proxmox akan di uji dan di buat perencanaan pada saat menjalankan server. Server akan di uji dalam beberapa skenario pengujian. adapun pada pengujian ini menggunakan beberapa skenario dalam melakukan pengujian, yaitu:

\section{1) Skenario Satu}

Dalam skenario ini bertujuan untuk menguji penggunaan CPU dan memory dalam 1 server atau os ataupun 2 server, atau 3 server yang berjalan.

\begin{tabular}{|c|c|}
\hline 讜 CPU usage & $1.91 \%$ of $4 \mathrm{CPU}(\mathrm{s})$ \\
\hline 플 Load average & $0.09,0.09,0.08$ \\
\hline 佪 RAM usage & $8.68 \%(849.94 \mathrm{MiB}$ of $9.56 \mathrm{GiB})$ \\
\hline GD space(root) & $17.34 \%(16.30 \mathrm{GiB}$ of $93.99 \mathrm{GiB})$ \\
\hline
\end{tabular}

Gambar 3 : Tampilan penggunaan resource

Berdasarkan dari gambar diatas penggunaan memory saat ini adalah sebesar 849,94MB/9,56GB dan penggunaan CPU adalah sekitar $1,91 \%$. Kondisi resource ini adalah sebelum di jalankannya sistem operasi.

\begin{tabular}{|c|c|}
\hline 㰻 CPU usage & $5.85 \%$ of $4 \mathrm{CPU}(\mathrm{s})$ \\
\hline 三 Load average & $0.75,0.34,0.17$ \\
\hline 䱏 RAM usage & $28.47 \%(2.72 \mathrm{GiB}$ of $9.56 \mathrm{GiB})$ \\
\hline$\boxminus \mathrm{HD}$ space(root) & $17.34 \%(16.30 \mathrm{GiB}$ of $93.99 \mathrm{GiB})$ \\
\hline
\end{tabular}

Gambar 4 : Tampilan penggunaan resource

Berdasarkan dari gambar diatas penggunaan memory saat ini adalah sebesar 2,72GB/9,56GB dan penggunaan CPU adalah sekitar $5,85 \%$. Kondisi resource ini adalah di jalankannya satu sistem operasi.

\begin{tabular}{|c|c|}
\hline 䇏 CPU usage & $2.67 \%$ of $4 \mathrm{CPU}(\mathrm{s})$ \\
\hline 三 Load average & $0.34,0.34,0.21$ \\
\hline 四 RAM usage & $35.95 \%(3.44 \mathrm{GiB}$ of $9.56 \mathrm{GiB})$ \\
\hline$\Theta \mathrm{HD}$ space(root) & $17.34 \%(16.30 \mathrm{GiB}$ of $93.99 \mathrm{GiB})$ \\
\hline
\end{tabular}

Gambar 5 : Tampilan penggunaan resource

Berdasarkan dari gambar diatas penggunaan memory saat ini adalah sebesar 3,44GB/9,56GB dan penggunaan CPU adalah sekitar $2,67 \%$. Kondisi resource ini adalah di jalankannya satu sistem operasi.

\begin{tabular}{|c|c|}
\hline 諅 CPU usage & $2.72 \%$ of $4 \mathrm{CPU}(\mathrm{s})$ \\
\hline 폴 Load average & $0.27,0.27,0.21$ \\
\hline 䛛 RAM usage & $42.01 \%(4.02 \mathrm{GiB}$ of $9.56 \mathrm{GiB})$ \\
\hline HD space(root) & $17.34 \%(16.30 \mathrm{GiB}$ of $93.99 \mathrm{GiB})$ \\
\hline
\end{tabular}

Gambar 6 : Tampilan penggunaan resource

Berdasarkan dari gambar diatas penggunaan memory saat ini adalah sebesar 4,02GB/9,56GB dan penggunaan CPU adalah sekitar $2,72 \%$. Kondisi resource ini adalah di jalankannya satu sistem operasi.

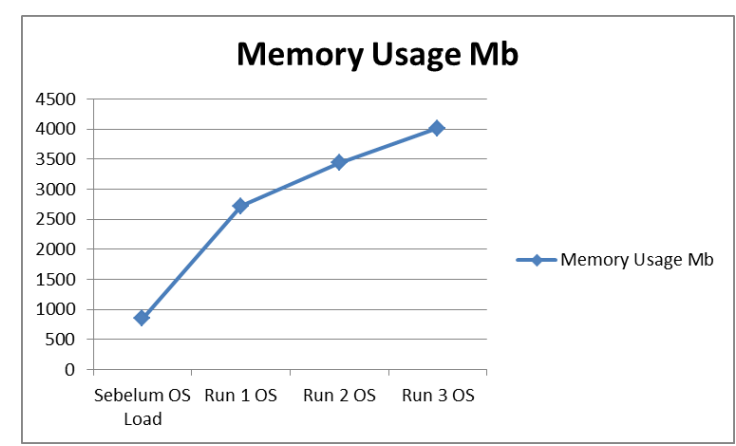

Gambar 7 : Grafik peningkatan memory

Terlihat dari grafik di atas bahwa peningkatan memory pada setiap load os atau dijalankannya OS, mulai dari belum dijalankannya OS sampai dijalankannya semua OS yang ada didalam proxmox tersebut, dari total 9,59GB Memory yang ada yang terpakai setelah dijalankan semua OS adalah sebanyak 4GB.

Statistik penggunaan memory juga dapat dilihat langsung pada terminal proxmox bisa dilihat melalui Putty dengan cara masuk menggunakan IP Address yang ada pada proxmox lalu memberikan perintah stats informasi, dapat dilihat seperti gambar dibawah ini :

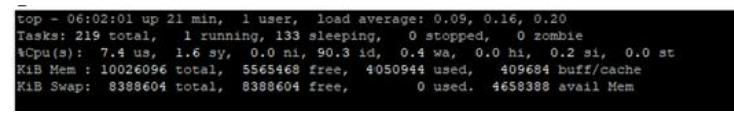

Gambar 8 : Tampilan penggunaan resource

Dari gambar diatas dapat dilihat status penggunaan memory yang dilihat dari sisi terminal proxmox dengan melakukan remote memakai PuTTy yang mana hasilnya sama apabila dilihat dari penjabaran sebelumnya. 


\section{2) Skenario Dua}

Pengujian pada skenario dua akan mengetahui pengujian akan dilakukan dengan aplikasi wireshark sebagai uji coba pada penelitian ini dan didapat dari rumus sesuai ketentuan dari sumber yaitu TIPHON.

\begin{tabular}{|c|c|c|c|c|}
\hline First packet: & \multicolumn{4}{|c|}{ 2019-03-10 01:07:41 } \\
\hline Last packet: & \multicolumn{4}{|c|}{ 2019-03-10 01:09:31 } \\
\hline Elapsed: & \multicolumn{4}{|l|}{ 00:01:50 } \\
\hline \multicolumn{5}{|l|}{ Capture } \\
\hline Hardware: & \multicolumn{4}{|c|}{ Intel(R) Core (TM) i3-6006U CPU @ 2.00GHz (with SSE4.2) } \\
\hline OS: & \multicolumn{4}{|c|}{ 64-bit Windows 10 (1803), build 17134} \\
\hline Application: & \multicolumn{4}{|c|}{ Dumpcap (Wireshark) 3.0 .0 (v3.0.0-0-g937e33de) } \\
\hline \multicolumn{5}{|l|}{ Interfaces } \\
\hline Interface & Dropped packets & Capture filter & Link type & Packet size limit \\
\hline Wi-Fi & $0(0 \%)$ & & Ethernet & 262144 bytes \\
\hline \multicolumn{5}{|l|}{ Statistics } \\
\hline Measurement & Captured & & Displayed & Marked \\
\hline Packets & 1755 & & $649(37.0 \%)$ & - \\
\hline Time span, $\mathrm{s}$ & 110.660 & & 66.395 & - \\
\hline Average pps & 15.9 & & 9.8 & - \\
\hline \multicolumn{2}{|c|}{ Average packet size, B 557} & & 687 & - \\
\hline Bytes & 977393 & & $446120(45.6 \%)$ & 0 \\
\hline Average bytes/ & 8832 & & & - \\
\hline & & & 6719 & \\
\hline
\end{tabular}

Gambar 9 : Statistics Wordpress

Pada gambar diatas menjelaskan tentang statistics saat melakukan akses ke web wordpress yang ada di OS CentOS disitu dapat dilihat throughput yang didapat yaitu 70k bits/s apabila dicari dari ketentuan rumus sebagai berikut :

Throughput = Jumlah data yang dikirim $/$ Waktu pengiriman data

977393/110,66 Throughput $=8,832 \mathrm{bit} / \mathrm{s}$

1 Bytes $=8$ bit $=8,832 \times 8=70,656$

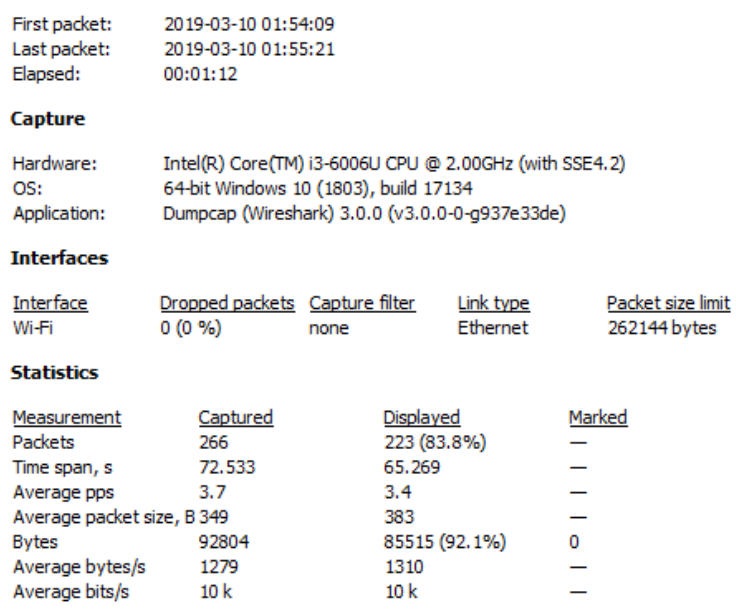

Gambar 10 : Statistics Moodle

Pada gambar diatas menjelaskan tentang statistics saat melakukan akses ke web moodle yang ada di OS Ubuntu disitu dapat dilihat throughput yang didapat yaitu $10 \mathrm{k}$ bits/s apabila dicari dari ketentuan rumus sebagai berikut :

$$
\begin{aligned}
& 92804 / 72,533=1279 \times 8=10 \mathrm{k} \mathrm{bit} / \mathrm{s} \\
& 1 \text { Bytes }=8 \mathrm{bit}=8,832 \times 8=70,656
\end{aligned}
$$

\begin{tabular}{|c|c|c|c|c|}
\hline First packet: & \multicolumn{4}{|c|}{ 2019-03-10 02:29:49 } \\
\hline Last packet: & \multicolumn{4}{|c|}{ 2019-03-10 02:31:19 } \\
\hline Elapsed: & \multicolumn{4}{|c|}{$00: 01: 30$} \\
\hline \multicolumn{5}{|l|}{ Capture } \\
\hline Hardware: & \multicolumn{4}{|c|}{ Intel $(R)$ Core $(T M)$ i3-6006U CPU @ $2.00 \mathrm{GHz}$ (with SSE4. 2) } \\
\hline OS: & \multicolumn{4}{|c|}{ 64-bit Windows 10 (1803), build 17134} \\
\hline Application: & \multicolumn{4}{|c|}{ Dumpcap (Wireshark) 3.0 .0 (v3.0.0-0-g937e33de) } \\
\hline \multicolumn{5}{|l|}{ Interfaces } \\
\hline Interface & Dropped packets & Capture filter & Link type & Packet size limit \\
\hline$\overline{\text { Wi-Fi }}$ & $0(0 \%)$ & & Ethernet & 262144 bytes \\
\hline \multicolumn{5}{|l|}{ Statistics } \\
\hline Measurement & Captured & \multicolumn{2}{|c|}{ Displayed } & Marked \\
\hline Packets & & & $725(96.9 \%)$ & $\frac{\text { Marked }}{-}$ \\
\hline Time span, s & 90.462 & \multicolumn{2}{|c|}{90.462} & - \\
\hline Average pps & 8.3 & & 8.0 & - \\
\hline \multicolumn{2}{|c|}{ Average packet size, B 623} & & 637 & - \\
\hline Bytes & 465957 & & $462138(99.2 \%)$ & 0 \\
\hline Average bytes/s & 5150 & & 5108 & \\
\hline Average bits/s & \multicolumn{3}{|c|}{$40 \mathrm{k}$} & 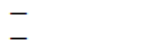 \\
\hline
\end{tabular}

\section{Gambar 11 : Statistics Wikimedia}

Pada gambar diatas menjelaskan tentang statistics saat melakukan akses ke web Wikimedia yang ada di OS Debian disitu dapat dilihat throughput yang didapat yaitu $41 \mathrm{k}$ bits/s apabila dicari dari ketentuan rumus sebagai berikut :

$465957 / 90,462=5150 \times 8=41200 \mathrm{bit} / \mathrm{s}$

\section{Throughput (k) (bit/s)}

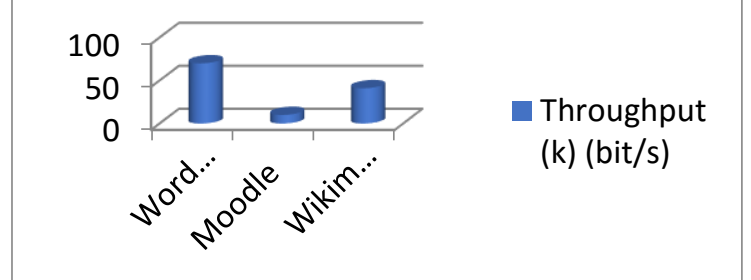

Gambar 12 : Grafik Throughput

Dari grafik di atas menjelaskan throughput yang ada pada masing-masing OS tersebut yang diakses dari sisi client, dapat dilihat throughput pada wordpress $70 \mathrm{k}$ bit/s pada moodle 10k bit/s dan Wikimedia $41 \mathrm{k} \mathrm{bit/s,}$ semakin besar nilai throughput maka semakin bagus untuk melayani request dari user. 


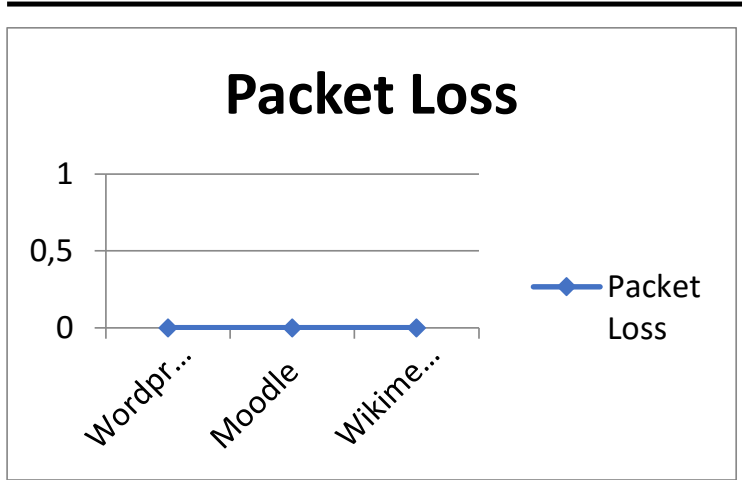

Gambar 13 : Grafik PacketLoss

Dapat disimpulkan dari grafik di atas tentang paketlossnya yaitu 0 tidak ada paket yang gagal dikirim maupun diterima.

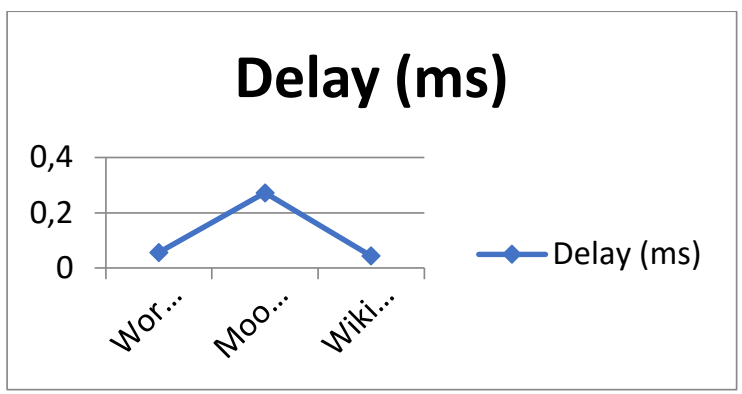

Gambar 14 : Grafik delay

Berdasarkan grafik di atas menjelaskan bahwa delay atau waktu tunda request ke server rata-rata berada di angka 0 yang artinya semakin kecil angka delay maka semakin bagus.

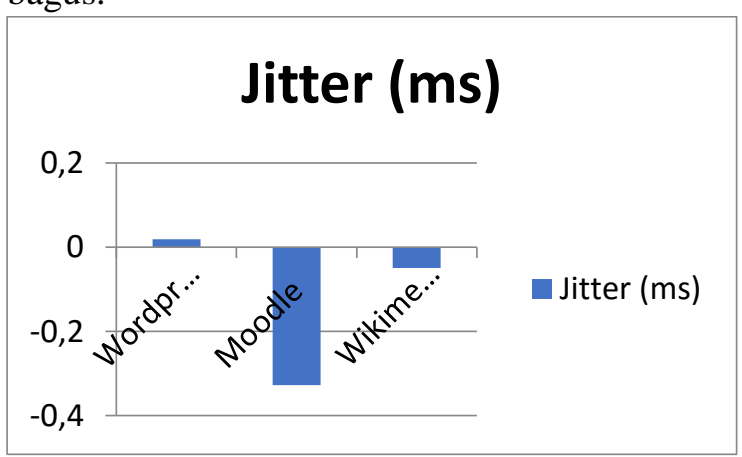

Gambar 15 : Grafik Jitter

Berdasarkan grafik di atas menjelaskan bahwa jitter dari semua server yang ada di masing-masing OS tersebut berada diangka -0 sampai dengan 0 yang dapat disimpulkan semakin kecil angka jitter maka semakin bagus kualitasnya.

\section{KESIMPULAN}

Berdasarkan penelitian dan uji coba pada sistem virtualisasi server proxmox dapat di tarik beberapa kesimpulan, sebagai berikut :

1. Berdasarkan pengujian yang dilakukan beban dari penggunaan memory dan load CPU pada server proxmox dimulai dari running tanpa menjalankan server penggunaan memory $849,94 \mathrm{MB}$ dari $9,56 \mathrm{~GB}$ dan $1,91 \%$ CPU, running satu server 2,72GB dari 9,56GB dan 5,85\% CPU, running dua server 3,44GB dari 9,56GB dan 2,67\% CPU, running tiga server $4,02 \mathrm{~GB}$ dari $9,56 \mathrm{~GB}$ dan $2,72 \%$ CPU.

2. Dari pengujian yang dilakukan maka didapatkan hasil throughput dari wordpress 70,656bit/s, pada moodle 10,000bit/s, 42,200bit/s. untuk packetloss 0 yang artinya tidak ada packetloss yang gagal terkirim, kemudian untuk delay dan jitter menyentuh diangka 0 semakin kecil delay dan jitter maka termasuk dalam kategori sangat bagus.

3. Diterapkannya virtual server menggunakan proxmox untuk mengoptimalkan resource.

\section{DAFTAR PUSTAKA}

[1] Faredha. A. R. dkk., 2017, Analisis Throughput dan Skalabilitas Virtualized Network Function VyOS Pada Hypervisor VMware ESXi, XEN, dan KVM. JURNAL INFOTEL, ISSN : 2085-3688.

[2] Setyo. P.W. dkk., 2015., Pusat Data Privat Virtual Pemerintah Berbasis Komputasi Awan. Volume 6 No. 2 November 2015 ISSN: 2087-0132.

[3] Soni, Y. Prayudi, and B. Sugiantoro, "Teknik Akuisisi Virtualisasi Server Menggunakan Metode Live Forensic," Teknomatika, vol. 9, no. 2, 2017.

[4] D. Sudyana, R. T. Putra, and S. Soni, "Digital Forensics Investigation on Proxmox Server Virtualization Using SNI 27037: 2014," Sink. - J. Publ. 
Informatics Eng. Res., vol. 3, no. 2, 2019.

[5] Maksum, A. dan Listiyoko, L., 2017, Implementasi Proxmox High Availability Server untuk Meningkatkan kinerja Website kampus., eISSN 25276050 .

[6] Arif. F. R. M., 2016, Implementasi Cloud Computing Menggunakan OpenVZ dalam Perkuliahan Praktikum Sistem Operasi, Vol: 5, No. 1, Maret 2016. ISSN: $2302-2949$.

[7] Prasandi. T. dan Whisnumurti., 2015, Virtualisasi sederhana menggunakan Proxmox. Chandramouli Reddy, Suchithra R, (2016), Virtual Machine Migration in Cloud Data Centers for Resource management. International Journal Of Engineering And Computer Science ISSN:2319-7242 Volume 5 Issue 09 September 2016 Page No.18029-18034.

[8] Dimas. P. R., 2018, Implementasi dan Perbandingan Performa Proxmox dalam Virtualisasi dengan Tiga Virtual Server., Jurnal Manajemen Informatika,. Volume 8 Nomor 01 Tahun 2018, 79-85.

[9] Yuisar, dkk., 2015, Analisa dan Pemanfaatan Proxy Server Sebagai Media filtering dan Caching pada Jaringan Komputer. Jurnal Media Infotama Vol. 11 No. 1, Februari 2015 